\title{
Mujeres en los modelos sociales y las estructuras de poder del sureste de Iberia (siglos V-IV a. $n$. e.): una lectura desde los espacios funerarios*
}

\author{
Women in the social models and power structures of southeastern Iberia $\left(5^{\text {th }} \mathrm{BC}-4^{\text {th }} \mathrm{BC}\right)$ : \\ a reading from funeral spaces
}

Ignasi Grau Mira ${ }^{a}$ y Alba Comino Comino ${ }^{b}$

\section{RESUMEN}

El papel de las mujeres en las sociedades ibéricas ha sido evaluado desde diferentes perspectivas. Este estudio revisa la participación de las mujeres en las estructuras de poder a partir de las relaciones espaciales y los discursos simbólicos materializados en cinco necrópolis del sureste de Iberia, fechadas entre los siglos V y IV a. n. e. Se observa que algunas de las tumbas más relevantes que vertebran el espacio funerario pertenecen a parejas o mujeres y construyen complejas genealogías para articular las relaciones sociales de tipo clientelar. Desde esta perspectiva, se identifican rasgos de las Sociedades de Casas en los modelos sociales del área de estudio como, por ejemplo, la legitimización de la descendencia bilateral o la coexistencia de diversas tumbas poderosas, que remite a estructuras heterárquicas.

\begin{abstract}
The role of women in Iberian societies has been evaluated from different perspectives. In this study, we review the participation of women in power structures by examining spatial relationships and symbolic discourses materialized in five necropolises in the southeast of Iberia, dated between the $5^{\text {th }} B C$ and $4^{\text {th }} B C$. Thus, it is observed that some of the most important tombs that in these funerary spaces belong to couples or women and build complex genealogies that articulate patron-client social relationships. From this perspective, features of House Societies are identified in the social models of the study area, such as, for example, the legitimization of bi-
\end{abstract}

lateral descent or the coexistence of various powerful tombs, evidence of heterarchical structures.

Palabras clave: sureste de la península ibérica; Edad del Hierro; necrópolis; Arqueología de género; Sociedades de Casas.

Key words: southeast Iberia; Iron Age; necropolis; Gender Archaeology; House Societies.

\section{INTRODUCCIÓN: MUJERES EN LOS MODELOS SOCIALES Y LAS ESTRUCTURAS DE PODER DEL SURESTE DE IBERIA}

En las últimas décadas, el desarrollo de las arqueologías de género, feminista, de mujeres y queer, así como la aplicación de sus enfoques y metodologías a la Protohistoria de la península ibérica, ha supuesto un importante avance en la investigación sobre el papel de la mujer en las sociedades ibéricas, y en especial en el ámbito funerario. No es un tema de estudio novedoso, ya que dos de los iconos iberos son las damas de Elche y Baza, aunque se aprecia su efecto en la reversión del sesgo androcéntrico que ha impregnado parte del relato sobre la cultura ibérica. Desde esta perspectiva, se han llevado a cabo proyectos de investigación (Prados Torreira et al. 2011), congresos (Prados Torreira et al.

\footnotetext{
* Este trabajo se ha realizado en el marco del proyecto de investigación PROMETEO/2019/035, "LIMOS. LItoral y MOntañaS en transición: arqueología del cambio social en las comarcas meridionales de la Comunidad Valenciana”, financiado por la Generalitat Valenciana. IP: Sonia Gutiérrez Lloret.

a Universidad de Alicante, I. U. Investigación en Arqueología y Patrimonio Histórico (INAPH). Cta. San Vicente s/n. Ap. Correos 99. 03080 Alicante. Correo e.: ignacio.grau@ua.es https://orcid.org/0000-0001-8470-6315

b Investigadora independiente. C/ Marqués de Mudela 46. 13600 Alcázar de San Juan. Ciudad Real. Correo e.: alba.comino2@gmail.com https://orcid.org/0000-0003-2730-3274

Recibido 23-IV-2021; aceptado 21-VI-2021.
} de uso y distribución "Creative Commons Reconocimiento 4.0 Internacional” (CC BY 4.0) 
2012) y exposiciones (Rueda et al. 2016; Castelo et al. 2017), se han implementado programas de dinamización patrimonial (Herranz et al. 2016; Ripollés Adelantado et al. 2016), se han defendido tesis doctorales ${ }^{1} \mathrm{e}$, incluso, se ha recurrido al relato de ficción (González Reyero et al. 2020) para integrar en los discursos históricos las etapas de la vida de las mujeres, incluida la muerte, en la sociedad ibérica.

Un simple análisis bibliográfico refleja las numerosas investigaciones publicadas sobre las problemáticas en torno a las mujeres iberas a partir del registro arqueológico de las necrópolis. Se enfatiza la visibilización de las mujeres, ya sea mediante la definición de las identidades de género (Izquierdo Peraile y Prados Torreira 2004; Izquierdo Peraile 2007; Prados Torreira 2007, 2012; Rafel 2007; Gualda Bernal 2018; García Cano y Gualda Bernal 2019), el imaginario femenino de la muerte (Díaz-Andreu y Tortosa 1998; Izquierdo Peraile 1999, 2008, 2012; Aranegui 2008; López Ruiz 2008; Gualda Bernal 2015a, 2015b) o la participación de las mujeres en los rituales funerarios (Izquierdo Peraile 1998; Rísquez y Hornos 2005; Rísquez y García Luque 2007a, 2012; Rísquez et al. 2010; García Cardiel 2017). Otro debate aborda el significado del armamento en tumbas de mujeres (Quesada 2010, 2012; Gualda Bernal 2014) y el rol de la pareja en la configuración de la aristocracia a partir del siglo IV a. $\mathrm{n}$. e. (Ruano Ruiz 1994; Rísquez y García Luque 2007b; Prados Torreira 2010; Ruiz et al. 2011).

La reivindicación del papel de la mujer obliga a repensar su participación concreta en la sociedad y las estructuras de poder ibéricas, más allá de su valoración cultural. A nuestro parecer, para ello es importante entender el funcionamiento de las sociedades ibéricas como Sociedades de Casas. González-Ruibal (2006) viene proponiendo esta caracterización para el caso de la península ibérica prerromana y Ruiz-Gálvez (2018) ha sugerido su posible aplicación a los iberos, a la vez que Ruiz y Molinos (2018) valoraban la existencia de algunos rasgos del modelo de Sociedades de Casas en la estructura del linaje gentilicio clientelar.

Vives-Ferrándiz (2013) introdujo la caracterización de los aspectos sociales siguiendo el modelo de Sociedades de Casas en el área suroriental de Iberia (Fig. 1). Sus argumentos se han desarrollado en trabajos en los que hemos participado (Bonet et al. 2015; Grau Mira y Vives-Ferrándiz 2018), donde se han abordado la configuración de los espacios domésticos, la organización del territorio y la articulación de los lugares de culto.

M. A. García Luque. Arqueología del género en la cultura ibera: una lectura desde la muerte. Tesis doctoral inédita. Universidad de Jaén, 2008.

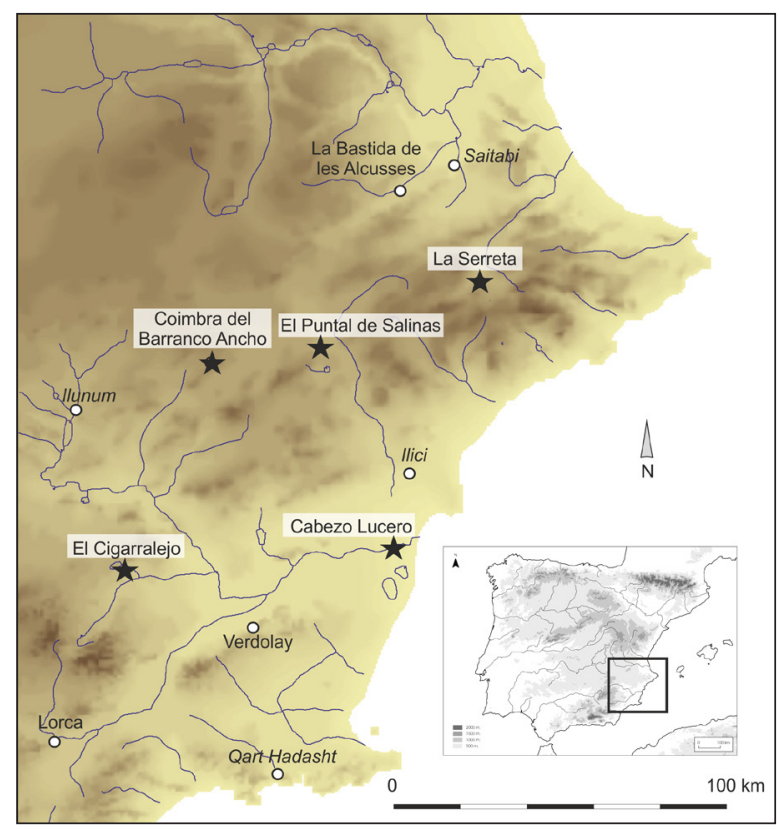

Fig. 1. Mapa de la península ibérica con el área de estudio, donde se localizan las necrópolis analizadas y los principales asentamientos ibéricos de época antigua y plena, siglos V-IV a. n. e. En color en la edición electrónica.

Ahora completamos esos aspectos con una inspección de las áreas funerarias.

El germen de esta propuesta parte de la evidencia de que en la región de estudio no se produjeron fórmulas de organización social de carácter tan jerarquizado como las que caracterizan, p. ej., el mundo ibérico en la Alta Andalucía (Grau Mira 2007: 131-132), con sistemas de poblamiento mucho más centralizados y muestras más ostentosas de representación de las elites, que residen en destacados palacios como el de Puente Tablas (Ruiz 2008). Tampoco se detectan las muestras individualizadas del poder propias de poderosos linajes con aristócratas a la cabeza, sino más bien poderes corporativos propios de instituciones no personalistas. Todo ello se condice bien con el modelo de Sociedades de Casas.

El concepto de Sociedades de Casas fue introducido por Lévi-Strauss (1981: 150) para intentar comprender las relaciones de parentesco de los Kwakiutl y Yurok, que parecían combinar elementos de ascendencia tanto patrilineal como matrilineal. Como la investigación precedente sobre el papel de la mujer ibera se ha encargado de mostrar, poder y riqueza también se transmitirían por vía materna en la sociedad ibérica. Este punto de partida lleva a plantear que su modelo social fuera inclusivo con participación de ambos géneros en igualdad de condiciones. 
Para Lévi-Strauss, las Sociedades de Casas representaban una especie de etapa evolutiva donde el lenguaje del parentesco y la afinidad servían para expresar las nuevas realidades de la desigualdad social, a medida que se iban desarrollando jerarquías sociales más estratificadas situadas entre el parentesco y las clases (Lévi-Strauss 1981; González-Ruibal 2006: 144-146; González-Ruibal y Ruiz Gálvez 2016: 385386; Ruiz Gálvez 2018: 17-18). En cambio, nosotros compartimos los argumentos de Gillespie (2007: 30), para quien las Sociedades de Casas son un proceso y no tanto un tipo social distintivo entre el parentesco y las clases. Por esa razón las Sociedades de Casas están tan extendidas geográfica y cronológicamente (Joyce y Gillespie 2000; Chesson 2003; González-Ruibal 2006; Beck 2007; Driessen 2010). Las Casas enmarañadas en relaciones de competencia tienden a emerger en períodos de transformación estructural significativa (Carsten y Hugh-Jones 1995: 10; Waterson 1995: 54) que producen la metamorfosis de las sociedades en Sociedades de Casas y cuyo comportamiento puede revertirse cuando se modifican estas circunstancias (Gillespie 2007: 30). Los factores recurrentes y mutuamente asociados son el rápido cambio social, la transformación de las relaciones de propiedad y el surgimiento de formaciones sociales limitadas y competitivas. Estas condiciones caracterizan los procesos de configuración de las sociedades de Iberia durante el I milenio a. n. e. (Ruiz 2008; Sanmartí 2009; Bonet et al. 2015).

La ventaja competitiva de la organización en Sociedades de Casas es permitir acumular riqueza en su seno y disponer de ella en la construcción de prestigio y la captación de clientes, a través de regalos, festejos o dotes de novia. Se establece así una dinámica donde las familias y personas se constituirían en Sociedades de Casas para evitar una posición de desventaja social (Thomas 2015: 144-145). Ruiz y Molinos (2018) proponen que estos procesos condujeran a la formación de los linajes clientelares. Sin embargo, el modelo que comentamos es corporativo y sitúa la relevancia y la riqueza en un nivel superior al de los miembros que la componen. En el seno de las Casas se establecen jerarquías y hay familias principales, pero los valores corporativos mitigan estas distancias sociales, como defendemos para el área oriental de Iberia (Grau Mira 2019). Además, la combinación de la jerarquía interna de las Casas con el carácter heterárquico y competitivo entre ellas originaría nodos plurales de poder en la misma comunidad (Grau Mira y Vives-Ferrándiz 2018) frente a las formas unívocas propias de regímenes más jerarquizados como las pirámides clientelares (Ruiz 2008).

En las Sociedades de Casas, la estructura física de las viviendas sirve como vehículo para la transmisión de la propiedad, pero también de nombres, bienes y títulos a través de generaciones (Lévi-Strauss 1981: 150), y actúa como símbolo de la identidad colectiva. Además, el edificio en sí tiene una fuerza vital y no se compone solo de materia inerte. Hay numerosos ejemplos de rituales domésticos iberos que subrayan la relevancia de dotar a la casa de sustancias trascendentes que incrementen su importancia (Bonet 2010). Sin embargo, las Sociedades de Casas pueden materializarse también en espacios no domésticos como, p. ej., un monumento, un lugar de origen o un almacén mantenido por un grupo de cuidadores y habitado por los espíritus ancestrales (Waterson 1995: 54). Estos edificios pueden tener diversas funciones, desde lugares de reunión hasta espacios funerarios. Los ancestros son de importancia crítica para las Sociedades de Casas, por lo que sus restos mortales a menudo están presentes en estas estructuras, ya sea enterrados bajo el suelo o expuestos en el interior. Además, estos pueden adquirir una cualidad santificada, como huellas tangibles de la colectividad. De este modo, las tumbas pueden considerarse una forma material más duradera y con mayor poder simbólico debido a la presencia física de las generaciones antepasadas fundadoras. En las Sociedades de Casas, los ancestros son las personas que fundaron un grupo social particular, y de quienes los miembros de la Casa afirman descender, incluso aunque sea un discurso ficticio (Thomas 2015: 144-145). Este tipo de ascendencia se emplea principalmente para la construcción de la identidad compartida y la propiedad colectiva.

El papel específico de la generación fundadora ha sido propuesto en el modelo de linaje clientelar ibérico. Sin embargo, frente al protagonismo del príncipe en los linajes, en los que la mujer sanciona la figura de la madre o la esposa para constituir la familia nuclear (Ruiz y Molinos 2018), en este trabajo se reivindica que la ascendencia frecuentemente está representada por una pareja fundadora o, incluso, una mujer). Ello reclama fijar la atención en un modelo social más inclusivo donde las mujeres tuvieron un papel más relevante en las estructuras de poder del que se les ha atribuido hasta el momento.

\section{ESPACIOS FUNERARIOS, MARCADORES SIMBÓLICOS Y SOCIEDADES DE CASAS}

La consideración de que los grupos ibéricos funcionaron como Sociedades de Casas, al menos en algunos territorios y momentos, permite evaluar los espacios funerarios como materialización de estas estructuras sociales y definir las génesis y dinámicas del poder a partir de tres elementos interrelacionados: heterarquía, bilateralidad y corporativismo. 
Las necrópolis suelen contar con varios focos destacados. Es raro que solo una tumba sobresalga claramente en un momento determinado. Los núcleos de poder existentes pueden considerarse simultáneos, o al menos correspondientes a una misma generación y, por tanto, indicarían una cúspide con diferentes poderes heterárquicos, articulados en sentido horizontal, en competencia. Podría pensarse que las tumbas ubicadas en la cima se sucediesen en el tiempo y pertenecieran a un mismo linaje dominante, pero a veces su cercanía temporal hace difícil sostener una secuencia.

Los nodos de poder se expresan en masculino y femenino, como manifiestan las tumbas dobles. Este fenómeno concurre en un buen número de ejemplos de la Alta Andalucía y el sureste ibérico, desde Peal del Becerro hasta Corral de Saus, pasando por los casos excepcionales de El Cigarralejo y Cabezo Lucero. Estos enterramientos se han identificado con las tumbas de la pareja fundadora y la expresión de la familia nuclear legitimadora del linaje gentilicio clientelar (Rísquez y García Luque 2007b). Se trate o no de verdaderas parejas conyugales, estas tumbas señalan el valor de ambos linajes como transmisores legítimos de bienes y derechos a la descendencia. En un sentido más amplio, indicarían que el lenguaje material del poder era multivocal e integraba valores múltiples, algunos masculinos y otros femeninos. Esa doble expresión llevaría a considerar legítima la transmisión por vía masculina o femenina sin necesidad de privilegiar la primera.

Los valores expresados en las tumbas son individuales y también definen elementos de carácter corporativo que identifican a una unidad social superior a la de las personas enterradas. Normalmente el poder mostrado en las tumbas se relaciona con la posición de la familia o el linaje, en genérico. A nuestro parecer, esa unidad social superior puede ser la Casa, como agregación que aúna los componentes de familia bilateral y parentesco metafórico, propios de las relaciones más allá de las exclusivamente consanguíneas. La Casa utiliza expresiones con ambigüedad de género en un marco inclusivo, remitiendo a lenguajes de un poder cuyos valores a la vez masculinos y femeninos señalan su carácter de unidad social superior. Eso explicaría la anomalía de encontrar tumbas de mujeres con armas o de varones con elementos textiles. También las tumbas dobles que incorporan objetos tipificados como masculinos y femeninos expresarían ese valor plural: además de sumar dos individualidades, muestran un poder enmarañado.

Los componentes expuestos sugieren la posibilidad de reconocer la forma de ordenación en Casas de las sociedades ibéricas mediante las lecturas del espacio y los discursos simbólicos funerarios.

El espacio como estructurante de nodos de poder ha sido una aportación fundamental en el análisis social ibérico. El ejemplo paradigmático es su aplicación a la necrópolis de Baza (Ruiz et al. 1992; Ruiz y Molinos 2018). Este estudio identificó las tumbas de los príncipes de la cúspide social, las áreas de los clientes y de su parentela, dispuestas en radios a cierta distancia, y los objetos que circularon para formalizar las relaciones sociales. A partir de este modélico análisis pretendemos probar que ambos géneros, y no solo los basados en el linaje del príncipe, participaron en el mecanismo para formalizar redes mixtas.

La posibilidad de amortizar bienes en las tumbas indicaría el acceso diferencial a la riqueza por lo que su cuantificación permite el reconocimiento de gradientes de poder económico, estatus y relevancia social de forma genérica (Quesada 1989). Sin embargo, son los objetos los que, interrelacionados mediante tramas de significados, permiten leer los discursos de poder y la construcción de la imagen de la persona enterrada a partir del lenguaje de la materialidad. Este planteamiento se ha aplicado al análisis de las armas, mediante el rol del guerrero y los valores marciales. En cambio, se han oscurecido discursos que consideramos equivalentes y no ordenados jerárquicamente referidos a campos simbólicos, como el banquete, o relacionados con elementos atribuidos al ámbito femenino, como el tejido.

A continuación, vamos a analizar las manifestaciones del ritual funerario en el registro arqueológico de cinco de las necrópolis más representativas del sureste de Iberia entre los siglos V y IV a. n. e., su momento de mayor desarrollo. Todas ellas disponen de publicaciones con informaciones detalladas de sus ajuares, de las relaciones espaciales y secuenciales de los hechos funerarios y de carácter paleoantropológico (sexo y edad de las personas enterradas).

Asumimos que el sujeto del duelo en el ritual funerario es la comunidad, centrando nuestra atención en los ecos temporales que genera su puesta en escena en el marco de las Sociedades de Casas. De este modo, como indica Rosa (2019: 76-77), observaremos cómo los rituales configuran ejes socioculturales de resonancia a través de los que se experimentan relaciones de resonancia verticales (con las divinidades y el tiempo), horizontales (con la comunidad) y diagonales (con las cosas).

\section{TUMBAS Y NECRÓPOLIS EN EL SURESTE}

\subsection{Cabezo Lucero}

Cabezo Lucero (Guardamar de Segura, Alacant) es un poblado fortificado ubicado en un cerro sobre la margen derecha de la desembocadura del río Segura. Este ámbito geográfico cuenta con una dilatada ocu- 
pación protohistórica que arranca en los sitios fenicios del Cabezo Pequeño del Estaño y La Fonteta. A partir del siglo $\mathrm{V}$ a. n. e. continúa en los poblados ibéricos de El Oral y Cabezo Lucero, aunque los datos disponibles de este último apenas bastan para definir sus rasgos.

La necrópolis está articulada por cuatro tipos de estructuras de piedra orientadas N-S y E-O con ligeras variaciones (Fig. 2): basamentos de estatuas, estructuras tumulares, plataformas de cremación y empedrados que sellan las fosas cinerarias. Las primeras son las más numerosas $\mathrm{y}$, con diferencia, de mayor trascendencia en el paisaje funerario y en la estructuración de la necrópolis (Aranegui et al. 1993: 69; Uroz y Uroz: 2010: 95-96). Predominan las estatuas de toros, pero también hay esfinges y figuras humanas. Como ya señaló Izquierdo Peraile (2000: 148-149), no aparecen recubriendo tumbas específicas, lo que es una diferencia trascendente respecto a otros monumentos funerarios, como los pilares-estela. Este peculiar paisaje funerario incluso se ha considerado un "cuerpo extraño" en el panorama funerario ibérico (Uroz y Uroz 2010: 99). De este modo, los monumentos iniciales de la necrópolis han de interpretarse en relación con unidades sociales superiores a los individuos, es decir, con un probable significado corporativo. Bien pudiera tratarse de contenedores simbólicos de las Casas o de sus segmentos representados en la necrópolis.

Tres componentes definen la particular configuración de los monumentos funerarios: elementos supraindividuales que remiten a unidades sociales inclusivas, varios poderes que se representan y compiten en el ámbito de exhibición de la necrópolis y una escultura es femenina, la Dama de Guardamar (Uroz y Uroz 2010: 97-98), lo que se condice bien con una figura ancestral fundadora de la institución.

Los primeros enterramientos de la necrópolis son tumbas singulares, especialmente la T. 75 (Aranegui et al. 1993: 241-245). Contiene una mujer joven y un adulto, al parecer varón, sepultados en sendas urnas cinerarias, orientalizante y de tipo "Cruz del Negro", poco frecuentes en la necrópolis y que pueden considerarse anacrónicas en el marco temporal de la tumba. Entre los objetos del ajuar sobresale una panoplia de tipo antiguo -formada por 1 caetra, 2 grebas de bronce, 1 cuchillo y 1 lanza-, 1 fíbula anular y 1 lékythos de figuras negras, que dataría la tumba en 490-460 a. n. e. Además de destacarse la figura del guerrero armado, este enterramiento se ha interpretado como la pareja fundadora que inauguraría el espacio funerario (Rísquez y García Luque 2007b: 267).

La segunda tumba (T. 84) del siglo V a. n. e., pero un par de generaciones posterior, muestra una estructura y composición semejante que han pasado desapercibidas quizá por la ausencia de armas. Es una sepultura doble de una mujer adulta madura y otro adulto de sexo

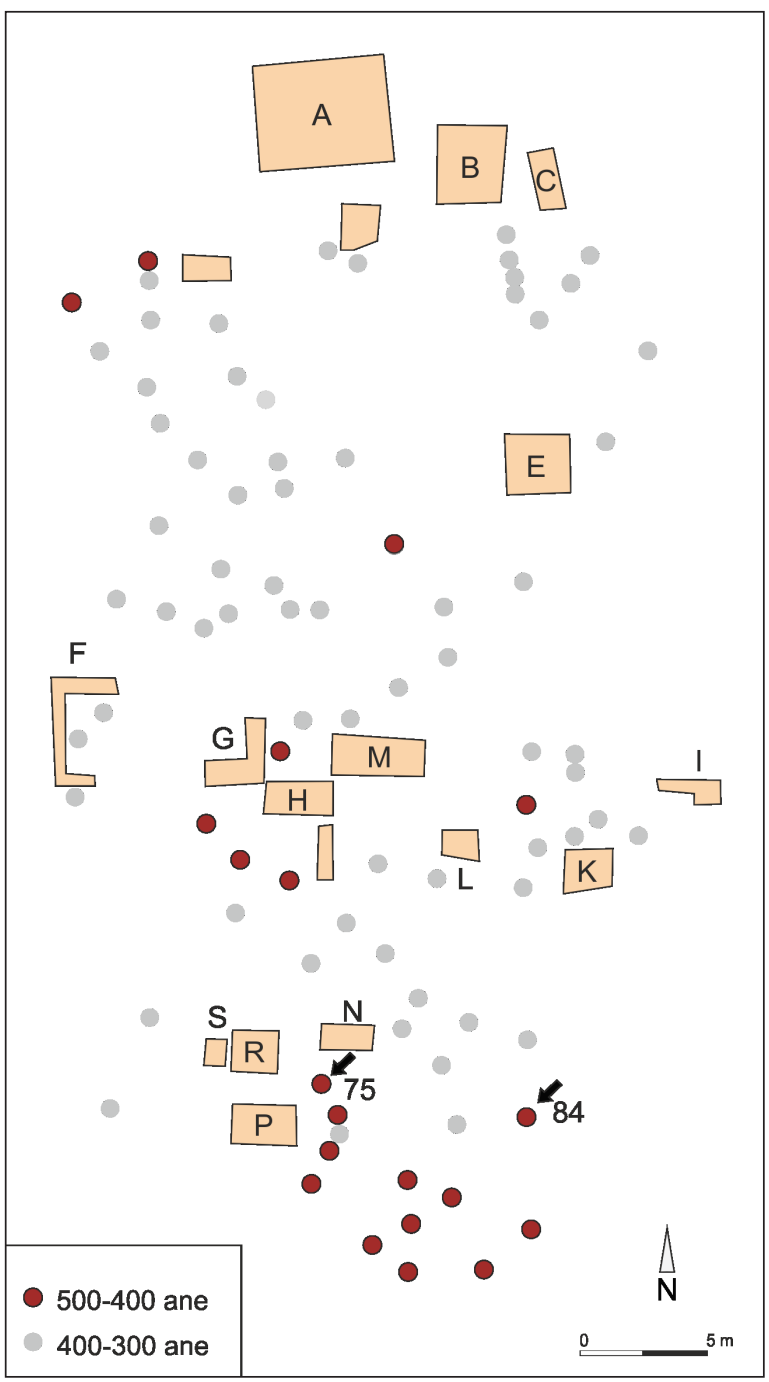

Fig. 2. Plano esquemático de Cabezo Lucero (Guardamar de Segura, Alacant, elaboración propia a partir de Aranegui et al. 1993: 26). En oscuro se señalan las tumbas más relevantes y con flechas las sepulturas dobles. En color en la edición electrónica.

indeterminado (Aranegui et al. 1993: 256-258, fig. 90, lám. 73-74). El ajuar comprende las urnas cinerarias, 3 platos, 1 yugo y 1 azuela de bronce miniaturizados, 2 pendientes de plata, partes de 2 fíbulas, 1 Neferte $[u] m$ egipcio de pasta vítrea, 2 pequeñas pirámides de piedra con signo inciso en la base y 481 cuentas de collar de hueso, vidrio y conchas de moluscos. Aquí, sin la elocuencia de las armas, destaca el marcado carácter ritual de los objetos incorporados al depósito funerario.

A nuestro parecer, ambas tumbas resaltan a través de campos simbólicos complementarios donde las mujeres sobresalen frente a una indefinición del elemento masculino. La secuencia cronológica que se extiende 
a lo largo del siglo $\mathrm{V}$ a. n. e., donde recordemos que solo aparecen 14 tumbas en el cementerio, señalaría que muy pocos miembros legitimaron su posición en el seno de la sociedad del momento y entre ellos las mujeres estaban bien representadas.

\subsection{El Puntal de Salinas}

La necrópolis de El Puntal (Salinas, Alacant) es un reducido espacio funerario vinculado a un pequeño poblado fortificado del valle del Vinalopó cuya ocupación se concentra en el siglo IV a. n. e. El hábitat y la necrópolis fueron excavados por Soler García a mediados del siglo XX, pero las evidencias se estudiaron décadas después (Sala y Hernández 1998). Las características del cementerio están generalizadas en otros de la región: un reducido número de tumbas donde las armas y los vasos de importación permiten una gradación de niveles de riqueza asociados con la jerarquización social de las personas enterradas $y$, por ende, de las familias de la comunidad.

Un eje NE-SO articula el espacio funerario enmarcado por una concentración central y las sepulturas T. 33 y T. 29-30, situadas de forma excéntrica y ligeramente alejadas del conjunto en ambos polos (Fig. 3). Esta separación se acentúa más si tenemos en cuenta que no se puede afirmar que los puntos que se inter-

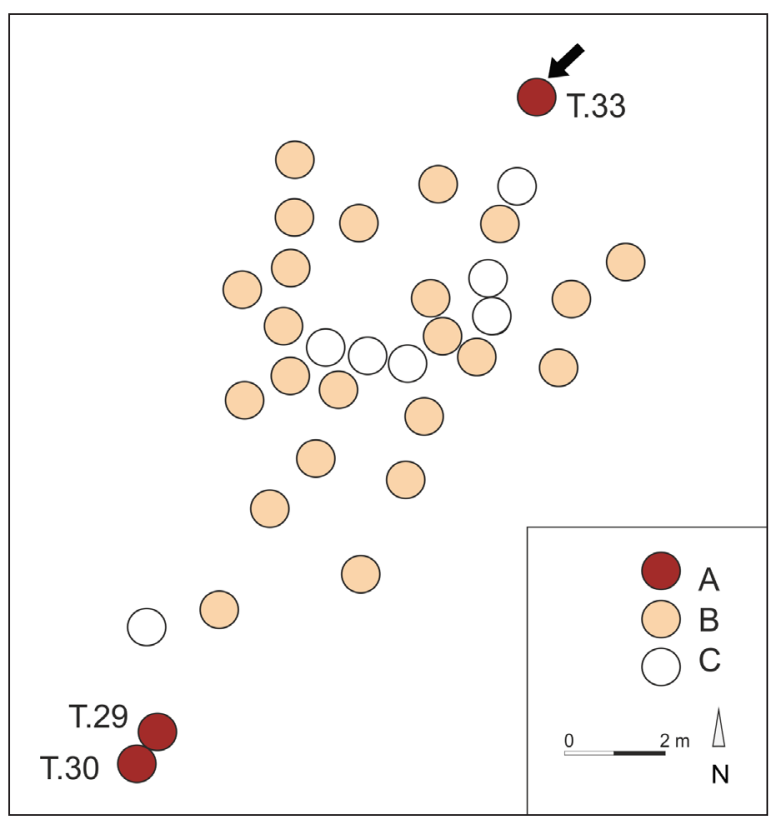

Fig. 3. Plano esquemático de El Puntal (Salinas, Alacant, elaboración propia a partir de Sala y Hernández 1998: fig. 32). A. Tumbas más relevantes; B. sepulturas; C. depósitos sin huesos; la flecha señala las sepulturas dobles. En color en la edición electrónica. calan entre los enterramientos citados y la agrupación sean propiamente tumbas, pues carecen de restos humanos (Sala y Hernández 1998: 248). De este modo, las T. 29-30 y T. 33 dispondrían de unos $4 \mathrm{~m}$ de respeto en torno a ellas. Estas tumbas excéntricas que ordenan el espacio pueden considerarse dobles, al menos, no son claramente individuales.

La T. 33 es un enterramiento doble en sendas urnas cinerarias. Por la cronología de los materiales del ajuar podría ser una de las primeras tumbas de la necrópolis. Una urna de orejetas contenía los restos de una mujer adulta, 1 abrazadera y 1 cuchillo afalcatado y la otra de perfil estilizado los restos de un varón adulto acompañado de 1 fíbula (Sala y Hernández 1998: 243-244). Ambas se depositaron sobre un lecho de cenizas con 2 cuchillos afalcatados, 1 plaquita de bronce, 1 botellita y 1 kýlix ático del tipo copa Cástulo entre otros objetos. Su disposición sugiere que no son ofrendas personales, sino asociables a ambos individuos, como parecen referir los 2 cuchillos situados en cada extremo del depósito. Así se enfatizaría el carácter doble de la tumba.

En el otro extremo de la necrópolis los puntos 2930 se identificaron durante la excavación como sendos túmulos de $1 \mathrm{~m}$ x $0,8 \mathrm{~m}$ aproximadamente. Después se consideraron un mismo conjunto los restos humanos (12 $\mathrm{g}$ en el punto 29) y los ajuares. La existencia de una panoplia completa y del hueso largo de un varón adulto ha llevado a considerarlo el enterramiento de un guerrero (Sala y Hernández 1998: 238). Además de las armas, se recuperaron 10 fusayolas de tipos diversos, 6 cuentas de collar, elementos de 1 caldero de bronce y un conjunto de recipientes cerámicos, entre los que destaca 1 pélike de figuras rojas y piezas ibéricas (Sala y Hernández 1998: 238).

En este ajuar, hay elementos asociados al discurso simbólico del ámbito bélico, el tejido, la comensalidad o la exhibición personal (p. ej. el collar de cuentas de vidrio). Se considere que esta tumba es doble - por los dos túmulos que la cubren- o no, los objetos del ajuar remiten a una lectura más compleja. Representan un amplio conjunto de elementos simbólicos, ambiguos en la asignación de género, pues entre ellos hay collares, armas y fusayolas. Esta misma composición ambigua se observa en la T. 1, donde aparecieron restos humanos, posiblemente de mujer, acompañados de 1 falcata, 1 cuchillo afalcatado, vasos de cerámica ática, elementos textiles y cuentas de collar (Sala y Hernández 1998: 223-225).

En definitiva, esta necrópolis de nuevo articula el espacio a partir de tumbas mixtas masculinas-femeninas bien a través de las evidencias humanas (T. 33), bien de la duplicidad de estructuras y discursos simbólicos (T. 29-30). Además, se puede proponer una secuencia cronológica donde la tumba inicial de una

Trab. Prehist., 78, N. ${ }^{\circ}$ 2, julio-diciembre 2021, pp. 309-324, ISSN: 0082-5638

https://doi.org/10.3989/tp.2021.12278 
pareja mantiene un esquema homólogo varias generaciones después. Ambos casos remiten a la participación de hombres y mujeres en las estructuras de poder.

\subsection{La Serreta}

El conjunto ibérico de La Serreta (Alcoi, Cocentaina y Penàguila, Alacant) consta de un gran poblado fortificado, un santuario territorial y una necrópolis centrada en el siglo IV a. n. e. Diversos estudios han valorado el papel central del enclave en el valle de Alcoi durante el siglo III a. n. e. (Grau Mira 2002).

El conocimiento de la necrópolis de La Serreta es parcial y desigual. Se han publicado en detalle las 15 tumbas que conforman el área central (Cortell et al. 1992), el armamento (Reig 2000) y el estudio paleoantropológico (Gómez Bellard 2011). A partir de estas evidencias, analizaremos algunos rasgos relevantes.

Nuestro estudio anterior (Grau Mira 2007: 130) se fijó en las armas, el elemento más conspicuo de los ajuares y el único disponible hasta entonces, para construir una gradación de los rangos sociales observables en la necrópolis. Había que completar esta lectura parcial de la documentación disponible con los discursos simbólicos construidos mediante otros elementos para comprender en toda su complejidad la estructura social que se dibuja en este espacio funerario.

En el área central de la necrópolis se ubican algunas de las tumbas más relevantes del conjunto, definiendo un epicentro simbólico plural que ordenaría el espacio de forma concéntrica (Fig. 4). Sobresalen la T. 1 de un varón adulto con un destacado conjunto de armas y la T. 11 con una estructura empedrada, parcialmente arrasada, que protegía los restos de un varón con falcata, caetra y escudo. Su depósito cinerario apareció cubierto por un excepcional umbo de bronce (Cortell et al. 1992). Junto a ellas estaba la T. 14, a nuestro parecer, una de las primeras de la necrópolis.

La T. 14 es un depósito triple de tres individuos de edades y géneros distintos en sus respectivas urnas que representan un hito en las necrópolis de cremación porque sus tamaños se corresponden con los cuerpos que contenían: adultos masculino y femenino e infantil (Gómez Bellard 2011: 107). Este conjunto puede ser interpretado como un grupo familiar, aunque esa supuesta filiación es difícil de comprobar en la actualidad. Los restos humanos se acompañan de una plaqueta de telar de hueso y elementos personales como sendas fíbulas anulares hispánicas o muestras de orfebrería, exclusivas de unas pocas tumbas de esta necrópolis (Cortell et al. 1992: 109).

La placa ósea interpretada como un tensor de tejido es un objeto reutilizado que remite a una antigua y compleja historia. Las perforaciones para las tramas de hilo se localizan por encima de los grabados de dos bovinos tumbados. La placa de origen etrusco es similar a un ejemplar de Vulci, que fue posteriormente perforada para darle un nuevo uso textil (Mata et al. 2020: 38, fig. 7). No es el único objeto que denota una larga historia. El rasgo más llamativo de esta sepultura es una urna de orejetas (Cortell et al. 1992: 91), propia de las necrópolis datadas en el siglo V a. n. e. como El Molar, La Solivella o Altea La Vella y, por tanto, un siglo anterior a la cronología de La Serreta. Está acompañada por una tapa que no corresponde al cierre de la urna: un plato de ala fenicio, cuyo perfil y especialmente su reducido ancho del borde sugieren una datación entre los siglos VI y V a. n. e. (Schubart 2002-2003: 58, fig. 16). De nuevo se observa que en una de las tumbas más antiguas de la necrópolis las urnas cinerarias muestran un claro anacronismo con el panorama del conjunto.

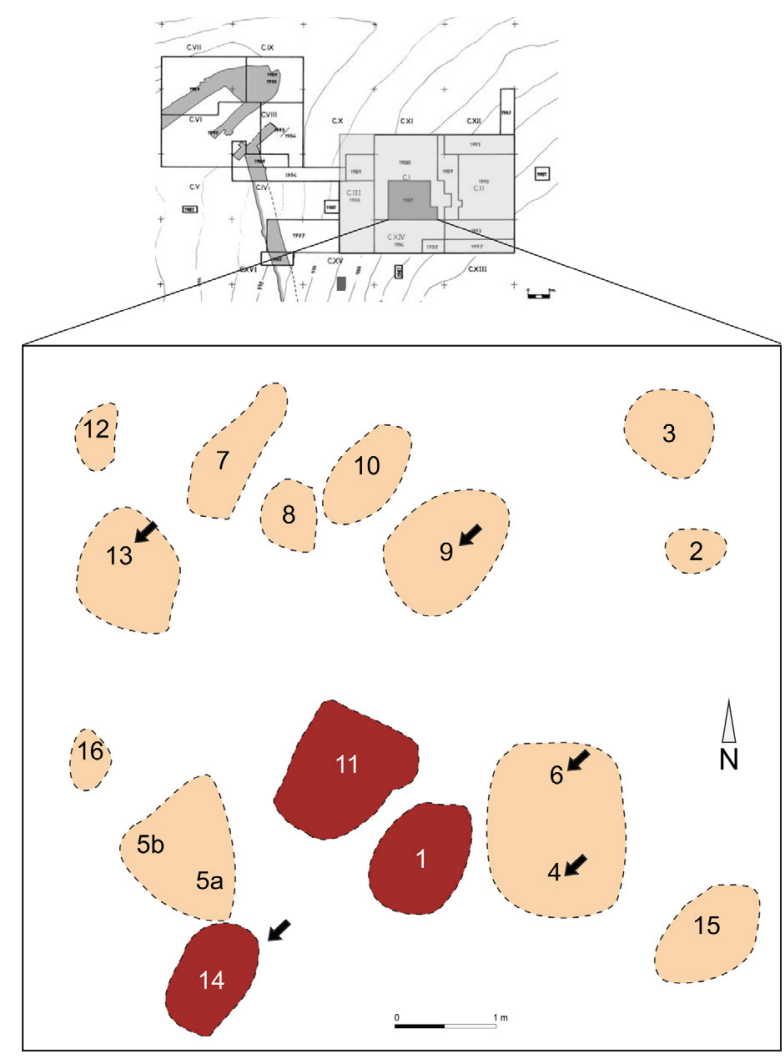

Fig. 4. Plano esquemático de La Serreta (Alcoi-Cocentaina-Penàguila, Alacant, elaboración propia a partir de Cortell et al. 1992: fig. 1). En oscuro se señalan las tumbas más relevantes y con flechas las sepulturas dobles y triples. En color en la edición electrónica.

\subsection{Coimbra del Barranco Ancho}

El complejo arqueológico de Coimbra del Barranco Ancho (Jumilla, Murcia) se compone de un área de 
hábitat, un santuario y tres necrópolis: La Senda, El Poblado y El Barranco (García Cano et al. 2016). La existencia de tres cementerios presupone unos condicionantes que estipulaban dónde la persona sería enterrada.

Nos centraremos en la necrópolis de El Poblado, la única que dispone de análisis osteológicos de un número representativo de tumbas (García Cano 1999; García Cano et al. 2008; Malgosa et al. 1999; Subirà et al. 2008; Subirà 2019). Es la más próxima al hábitat. Comenzó a excavarse a mediados del siglo XX, y desde 1977 las intervenciones arqueológicas de la Universidad de Murcia han documentado más de 200 tumbas de cremación secundaria, datadas entre el siglo IV y principios del siglo II a. n. e. (García Cano et al. 2016, con bibliografía anterior). La expansión de la necrópolis de El Poblado coincidiría con el progresivo decaimiento del área funeraria de La Senda (García Cano 1997: 22).

En el sector occidental de la zona $\mathrm{B}$ varios núcleos articulan el espacio funerario con aparente protagonismo de las tumbas dobles y las femeninas (Fig. 5). La mayoría de los enterramientos son fosas de tendencia ovalada cubiertas a veces por empedrados o estructuras de barro, aunque se han registrado construcciones de

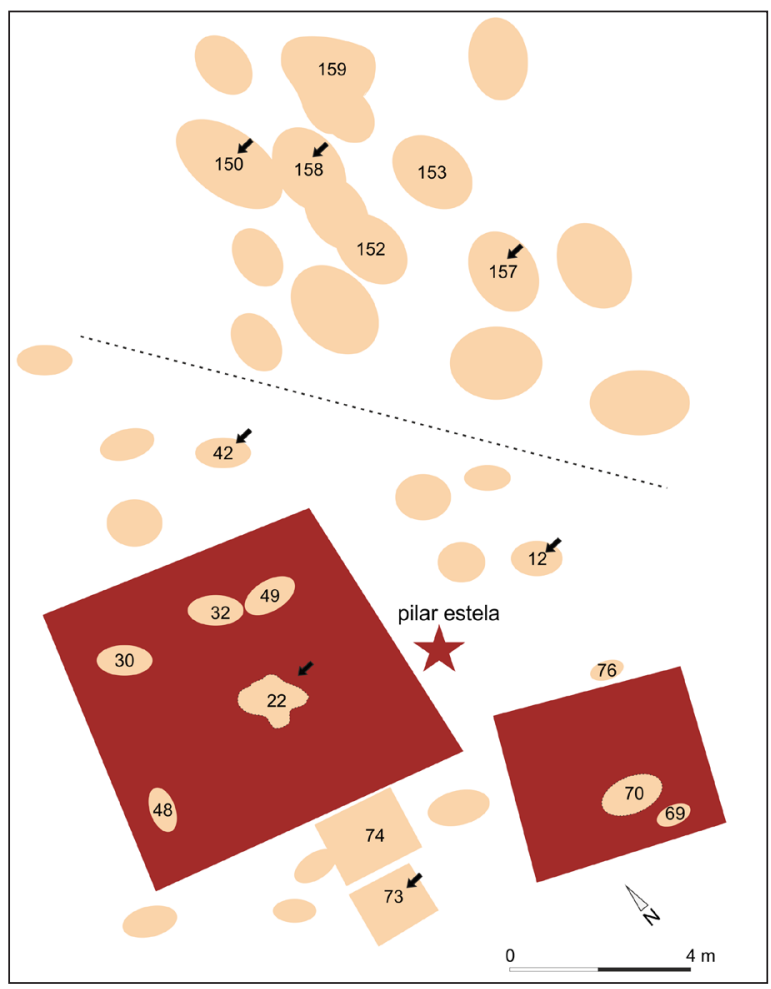

Fig. 5. Plano esquemático de Coimbra del Barranco Ancho (Jumilla, Murcia, elaboración propia a partir de García Cano et al. 2008). En oscuro se señalan las tumbas más relevantes y con flechas las sepulturas dobles. En color en la edición electrónica. mayor envergadura como los encachados tumulares de las T. 22 y T. 70 (García Cano 1997: 78).

En la T. 22, una de las más destacadas de la necrópolis de El Poblado, fueron enterrados un individuo adulto, probablemente masculino, junto a otro de sexo y edad indeterminados (García Cano 1999: 36-39; García Cano et al. 2008: 35, 38; Malgosa et al. 1999: 135) hacia 375-350 a. n. e. En torno a este enterramiento se originó un foco de poder, ya que el empedrado cuadrangular que lo cubría fue reutilizado sucesivamente por 16 tumbas desde el siglo IV al siglo II a. n. e. (García Cano et al. 2008: 35).

El número y variedad de elementos del ajuar de la T. 22 la convierten en una de las más ricas de la necrópolis (García Cano y Gualda Bernal 2019: 17). Sobresalen varios platos de cerámica ática de barniz negro e ibérica de barniz rojo, 2 pendientes de oro, varios fragmentos de punzones de hueso y 5 tabas. Predominan las armas. Han perdurado la empuñadura de 1 falcata, parte de su funda y del tahalí, 1 soliferrum, 2 puntas de lanza de hierro, 2 regatones y fragmentos de la manilla de 1 caetra. Los restos humanos fueron depositados directamente en la fosa y aparecieron mezclados con fragmentos de madera carbonizada y restos calcinados de fauna (García Cano et al. 2008: 35-38). Los ajuares de las cuatro tumbas que reutilizaron el túmulo en el siglo IV a. n. e. son similares al de la T. 22: tienen punzones de hueso, falcatas, puntas de lanza y, en las T. 30 y T. 32, el mismo tipo de plato de cerámica ática de barniz negro.

La T. 70, por su estructura y contenido del ajuar, ha sido atribuida a una importante personalidad de la comunidad, cuyo sexo no ha podido determinarse (García Cano et al. 2008: 105). Según Chapa (2008: 632-636) por el depósito funerario podría tratarse de una mujer desplazada desde su lugar natal con motivo de su matrimonio y fallecida antes de la celebración o de tener descendencia. Sobre esta sepultura se erigiría el conocido pilar estela (García Cano 1994, 1999: 4558; García Cano et al. 2008: 87-105), aunque Muñoz Amilibia (1987: 233) se decanta por su ubicación sobre el túmulo 22.

La T. 70 conserva un elevado número de elementos del ajuar. Destaca la vajilla cerámica ática de barniz negro e ibérica de barniz rojo y pintada con motivos geométricos, y 1 askós en forma de paloma. Son numerosas las fusayolas, los punzones de hueso, las tabas y los recipientes de madera. Entre los objetos de adorno personal sobresalen cuentas de collar de diferentes materiales, 7 anillos de bronce, 2 fíbulas anulares y 4 colgantes de pasta vítrea. Se han preservado restos de 1 capazo de esparto y semillas y frutos carbonizados. Los múltiples elementos que integran esta ofrenda funeraria invitan a pensar en los factores que determinaron cómo la comunidad construyó la memoria de la 
persona enterrada. El ajuar presenta similitudes con el de la tumba doble 200 de El Cigarralejo, pero diferentes lecturas apuntan a que este enterramiento correspondería a una mujer cuyo reconocimiento social dentro de la comunidad ni dependía, ni era compartido con un varón (Chapa 2008: 636; García Cano y Gualda Bernal 2019: 18).

En el sector oriental de la zona B de El Poblado se localiza otro epicentro hacia 375-350 a. n. e., a partir de las tumbas dobles 158 y 157 . El enterramiento 158 corresponde a una pareja. Los restos óseos calcinados atribuidos a una mujer joven se hallaron en la fosa y en el interior de un tarro cubierto por una escudilla de cerámica ibérica pintada con motivos geométricos, mientras que los del varón se encontraban depositados directamente en el subsuelo. Los objetos del ajuar incluían 1 falcata y parte de la funda y del tahalí, 1 punta de lanza, 1 regatón, 1 soliferrum, varios fragmentos de diferentes punzones de hueso, restos de fauna y 1 plato y 1 pátera de cerámica ibérica pintada (García Cano et al. 2008: 193-196).

La T. 150 se superpone ligeramente a la T. 158. Correspondía a un individuo adulto y otro juvenil de sexo indeterminado. La tumba destaca por su cuantioso ajuar. Entre sus componentes había 1 vaso ornitomorfo, 11 fusayolas, 1 colgante de oro, 2 anillos de plata, varias fíbulas, 1 agujón de bronce rematado por una figura de ave, numerosos punzones de hueso, diferentes tensores de telar, cuentas de collar de pasta vítrea y 1 amuleto egipcio con la representación de un enano Pateco Panteo (García Cano et al. 2008: 178-184). Por la riqueza del conjunto se ha paralelizado con la $\mathrm{T}$. 70 caracterizada como "principesca" (García Cano y Gualda Bernal 2019: 16).

Otra tumba en el área de influencia de la T. 158 es la T.153 perteneciente a una mujer (entre 25 y 35 años). En su ajuar destacan 1 askós en forma de ave de cerámica ibérica pintada, 1 bolsal ático de barniz negro, recipientes de cerámica ibérica pintada, 1 falcata y parte de su funda, 1 punta de lanza, 1 regatón, fragmentos de una caetra, 2 pendientes de oro en forma de media luna, 1 aguja de hierro y varios punzones de hueso (García Cano et al. 2008: 185-189). Se ha destacado la importancia y singularidad de esta cremación tanto por las armas como por la riqueza del ajuar (García Cano y Gualda Bernal 2019; Gualda Bernal 2014). Sobre esta tumba se ubica otra femenina, la T. 152, en la que se recuperaron 1 fusayola y 2 punzones de hueso junto a restos óseos de ovicáprido (García Cano et al. 2008: 185). La T. 159, perteneciente a una mujer adulta, también se superpone a la T. 158 . Su ajuar incluye 2 páteras de cerámica ibérica pintada, pero no se observan elementos relacionados con la producción textil (García Cano et al. 2008: 196). Hasta el siglo III a. n. e. se fueron superponiendo $y / 0$ adosando otras tumbas a las mencionadas

La T. 157 es el segundo enterramiento doble en torno al que se origina este foco. Corresponde a un adulto masculino y un individuo infantil. El ajuar contiene 1 falcata, restos de su funda, 1 manilla de caetra, 1 punzón de hueso, 1 olla de cerámica ibérica y restos de fauna (García Cano et al. 2008: 193). Sobre esta sepultura está la T. 156 donde fue enterrada una mujer adulta acompañada de varios recipientes áticos de barniz negro e ibéricos, 1 fusayola y punzones de hueso (García Cano et al. 2008: 192).

Los tres núcleos que hemos destacado se originan a mediados del siglo IV a. n. e. y en todos se observa la concentración del poder en las tumbas dobles y la relevancia de las mujeres. Estas se vinculan sobre todo con discursos sobre la producción textil y a veces con al ámbito bélico. El análisis de los ajuares en su conjunto reitera el significado polisémico de las armas, como se ha planteado en la T. 155 de la necrópolis de Baza (Quesada 2010: 165). Su presencia podría asociarse a los conceptos de estatus, poder y pertenencia a un grupo.

\subsection{El Cigarralejo}

La necrópolis de El Cigarralejo (Mula, Murcia) quizás sea una de las más estudiadas del sureste de la península ibérica. Un equipo coordinado por Emeterio Cuadrado inició en 1947 las intervenciones arqueológicas que se prolongaron hasta 1988 (Prada y Cuadrado 2019: 19). El conjunto integra un santuario, un espacio de hábitat $\mathrm{y}$, según testimonio de Cuadrado, otro posible cementerio en la parte baja de la ladera meridional donde se localiza el poblado (Cuadrado 1987: 44, lám. I; Lucas y Ruano 1998: 106).

El espacio funerario excavado ocupa una zona reducida donde se documentaron más de 500 tumbas en uso desde el siglo $\mathrm{V}$ hasta inicios del siglo I a. n. e. El periodo de máxima actividad fue el siglo IV a. n. e. (Prada y Cuadrado 2019: 19). Los restos óseos resultantes de la cremación se depositaron en urnas o en las propias fosas, que en muchos casos tienen empedrados tumulares, estelas o túmulos de adobe (Cuadrado 1987: 32-33).

Las características de la terraza en la que se ubica la necrópolis condicionan la ordenación del espacio. Las tumbas más antiguas articulan el espacio funerario en varios epicentros (Lucas y Ruano 1998: 109). Las denominadas "tumbas principescas" 200 y 277 conforman uno de estos núcleos. Se ubican en el sector más prominente, separadas del resto por un área de respeto delimitada por un muro de piedra (Fig. 6). Ambas se han fechado entre 425 y 375 a. n. e., aunque la T. 200 


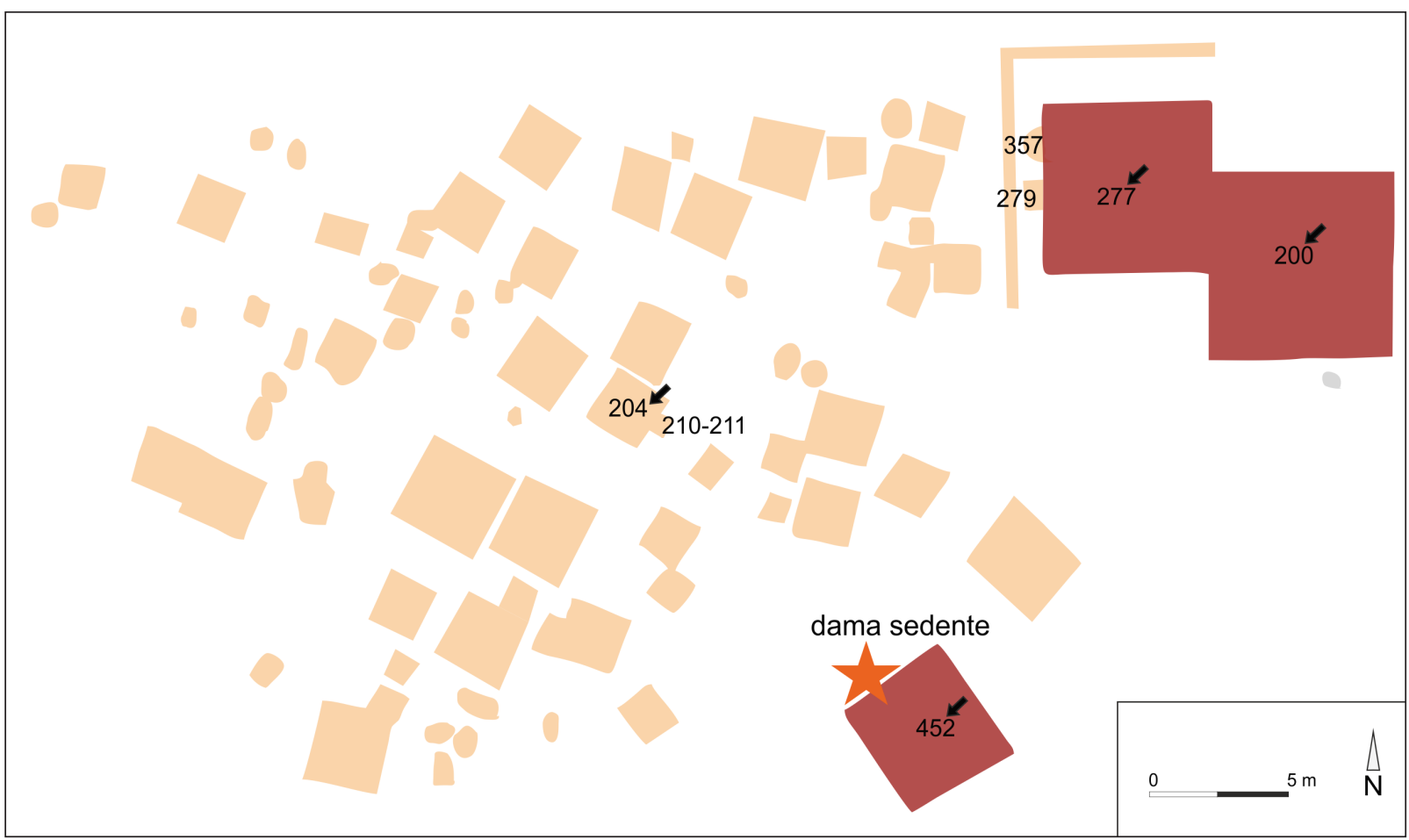

Fig. 6. Plano esquemático de El Cigarralejo (Mula, Murcia, elaboración propia a partir de Rísquez y García Luque 2007b). En oscuro se señalan las tumbas más relevantes y con flechas las sepulturas dobles. En color en la edición electrónica.

se superpone ligeramente sobre la T. 277, quizás expresando algún tipo de vinculación (Lucas 2001-2002: 151-152). Se localizaron sobre un espacio funerario anterior, ya que la construcción del túmulo 277 destruyó una tumba, atribuida a un varón adulto enterrado junto a 1 falcata (Cuadrado 1987: 470-474). El nuevo monumento funerario se superpuso a dos estructuras previas. Una era la T. 279, situada al mismo nivel que la tumba masculina citada, cuyo ajuar incluía 1 fíbula, 1 lanza y 1 fusayola (Cuadrado 1987: 488, 490). Otra era el empedrado de la T. 357 que Cuadrado (1987: 568-569) asignaba a una mujer enterrada junto a varios recipientes de cerámica ática de barniz negro e ibérica. Es decir, se constata una superposición de estructuras desde finales del siglo $\mathrm{V}$ hasta mediados del siglo IV a. n. e.

No se conocen análisis osteológicos de los restos conservados en las T. 200 y T. 277, pero, a partir del estudio de sus ajuares, se han identificado como sendas parejas (Cuadrado 1987: 39). La bibliografía posterior ha incidido en esta idea, interpretándolas como parejas fundacionales del linaje en el marco de una sociedad de carácter aristocrático clientelar (Rísquez y García Luque 2007b: 268-269; 2012: 261). La necrópolis de El Cigarralejo se ha convertido así en la base de multitud de estudios sobre la estructura social de la pobla- ción ibérica, principalmente durante el siglo IV a. n. e. (Santos 1989; Lucas y Ruano 1998: 111-13; Rísquez y García Luque 2007b).

En paralelo al foco de poder originado en el sector más elevado de la necrópolis, se creaba otro en el extremo suroeste del área funeraria, en torno al túmulo 452 , rematado por la escultura de una dama sedente (Cuadrado 1995). Este monumento funerario comparte códigos iconográficos con la Dama de Baza como, p. ej., el trono y el ave, pero difiere de ella por su exhibición al exterior formando parte del paisaje funerario. La T. 452 es un enterramiento doble, probablemente, de un varón y una mujer. Los restos óseos masculinos se introdujeron en una tinaja de cerámica ibérica pintada a cuyo alrededor se dispusieron varias armas. Entre los objetos del ajuar destacan 1 fusayola y 1 fíbula. La urna cineraria de la mujer, en cerámica ibérica pintada, imita una crátera de campana griega. El ajuar se distribuyó dentro y fuera de la urna. Constaba de cuentas de pasta vítrea, fusayolas, agujas de hueso para el pelo, 1 anillo y 1 fíbula, entre otros elementos (Prada y Cuadrado 2019: 82-83).

El encachado de la T. 452 también reutilizó fragmentos escultóricos, como sucedía en el empedrado y entorno del túmulo 200, donde elementos escultóricos y arquitectónicos formaban parte de la estructura ( $\mathrm{Lu}$ - 
cas 2001-2002: 152). Alrededor de este enterramiento datado hacia 400-375 a. n. e., se aglutinan sepulturas hasta el siglo II a. n. e. como, p. ej., las T. 447, T. 457, T. 438, T. 526 y T. 453 que se superponen al túmulo.

En la zona central de la necrópolis, hacia 400-375 a. n. e. se construyó el túmulo 204, un enterramiento doble perteneciente a una mujer menor de 25 años y un varón mayor de 35 años (Santonja 1985-1986: 35-36, 1993: 328-329). Sus ajuares se distribuían en el interior y en el exterior de la urna. Entre los objetos del ajuar atribuido a la mujer (T. 204 bis) destacan 4 fusayolas y 4 tabas. En el masculino (T. 204) 3 tabas y 1 fusayola aparecen con 1 falcata, 1 puñal, los restos de 1 escudo, 1 soliferrum y 2 fíbulas, entre otras piezas (Cuadrado 1987: 377-383).

En el área de influencia de la T. 204, según los análisis osteológicos, los enterramientos corresponden a mujeres (Rísquez y García Luque 2012: 264-265). La T. 210-211, p. ej., pertenece a una mujer de entre 17 y 20 años (Santonja 1993: 330-331) cuyo ajuar integra 2 fusayolas, 1 taba, 1 pendiente de plata, varias cuentas y 1 colgante de pasta vítrea y 3 anillos de bronce (Cuadrado 1987, 389-391).

Las tumbas dobles y las femeninas individuales analizadas muestran la recurrencia del lenguaje simbólico relacionado con la producción textil. Ya Rafel (2007: 122-128) indicó la aparición indistinta de los ítems textiles en tumbas individuales con o sin armas en El Cigarralejo. Esta perspectiva insiste en la importancia que el tejido podría tener en la comunidad como actividad productiva y elemento de prestigio, a la vez que pone en valor las habilidades para hilar y tejer, probablemente un aprendizaje transmitido de generación en generación.

\section{DISCUSIÓN}

Las necrópolis son espacios donde los aspectos privados y públicos se interrelacionan sin perfiles nítidos. Los actos litúrgicos para despedir a un miembro de la comunidad y propiciar su viaje al más allá, siguiendo los preceptos propios de la estructura religiosa ibera, se alinean entre los aspectos privados. Aquí queremos enfatizar los aspectos públicos relacionados con la definición de la organización social y la estructura de poder. En esas coordenadas, las necrópolis son espacios funerarios privativos de determinadas familias y grupos que construyeron y exhibieron su preeminencia social mediante el derecho a ser enterrados en lugares acotados, reducidos y en los que se materializaba la memoria.

Las necrópolis analizadas construyen y expresan las formas de agrupar al colectivo que está configurándose en unidades de tipo urbano, más amplias y complejas.
La naturaleza expansiva del proceso requiere mecanismos, como la clientela, de adscripción de miembros mediante fórmulas superiores al parentesco consanguíneo. Además, demanda instituciones que excedan el marco familiar y articulen esos nuevos vínculos, como el linaje clientelar o la Casa. Ambas instituciones comparten las relaciones clientelares, pero no la estructura de poder y transferencia de legitimación. Por ello, el análisis de las necrópolis permite desentrañar las fórmulas de construcción de poder y materialización de la autoridad política a partir de la ritualización simbólica de ciertas funciones.

En las comunidades ibéricas del sureste de la península ibérica esta autoridad y poder se formalizó y preservó a partir de funerales, rituales y enterramientos de determinadas personas, convertidas en un grupo de poder mediante la institucionalización de actos repetitivos y recurrentes en un mismo lugar funerario. La variedad de estructuras, prácticas y ajuares señalan un grupo diversificado en su composición social y sin excepcionales exhibiciones de riqueza, pero que muestra un estatus distinguido y claramente excluyente.

Estas prácticas funerarias reiterativas construyeron una genealogía para personas y familias concretas, pero también una memoria colectiva para el grupo social que se vinculaba a través de su relación con estos ancestros. Con las prácticas funerarias se construía el pasado del grupo mediante vínculos que trascendían el tiempo para conectar al pasado y proyectar al futuro la aspiración política de la unidad social. Proporcionarían una buena ocasión para mostrar el poder de la Casa mediante su exhibición en los funerales y los ritos asociados con la persona difunta que presidiría el cortejo de sus miembros engalanados o el consumo ritual de alimentos y bebidas poco frecuentes. Estas prácticas favorecerían la adscripción de miembros y familias a las Casas más poderosas en una competencia constante.

Una de las claves residiría en la configuración de esas genealogías y cómo la recurrente incorporación de nuevos miembros a la necrópolis creaba y recreaba el vínculo ancestral del grupo. Hemos fijado la atención en esas tumbas iniciales que, precisamente, ponen en marcha la filiación genealógica. Hemos podido comprobar cómo las fechas de sus urnas cinerarias no se corresponden con la datación de la necrópolis en el caso de los vasos orientalizantes de Cabezo Lucero o las urnas del Ibérico Antiguo en las necrópolis de Época Plena de El Puntal o La Serreta (Fig. 7). A nuestro parecer, son variaciones del fenómeno que A. Ruiz y M. Molinos (2018: 53) denominan la creación de "antepasados de memoria larga", que justifican el privilegiado estatus social de su descendencia. Y es que estas figuras ancestrales que iniciaron la genealogía suelen ser mujeres y hombres cuya unión sugiere la construcción del grupo social a partir de la importancia de la 


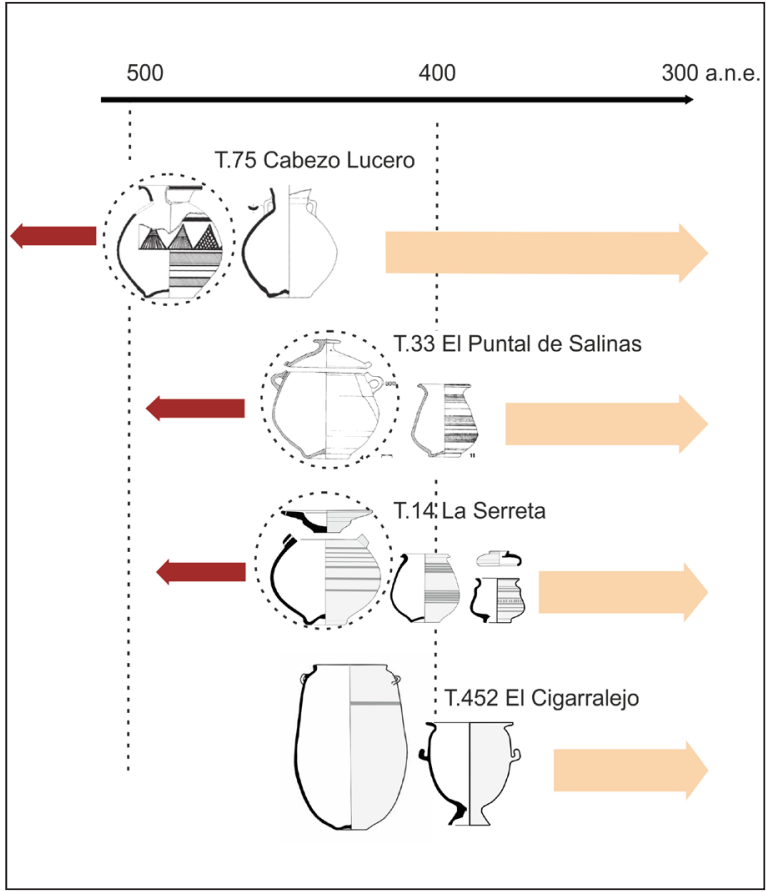

Fig. 7. Esquema con las urnas de las tumbas más relevantes estudiadas con enterramientos dobles y triple y que presentan urnas de cronología anterior a la fecha de enterramiento. En color en la edición electrónica.

pareja, es decir, a través de linajes bilaterales. La pareja no solo sanciona el matrimonio, como Rísquez y García Luque (2007b) han defendido para el caso ibérico. También transmite derechos, riqueza y legitimidad. De ahí que sean sepulturas dobles algunas de las tumbas más antiguas que articulan los espacios funerarios y cuenten con elementos que remiten a un tiempo anterior al del funeral de los difuntos.

Según la articulación espacial de algunas de estas necrópolis, coexisten varias unidades sociales semejantes cuyos referentes funerarios estarían disgregados. Como resultado varias necrópolis se relacionan con el poblado. Esto ocurre con las de Coimbra del Barranco Ancho o El Cigarralejo, donde además de la necrópolis conocida y publicada podría haber un segundo espacio funerario al oeste del poblado (Cuadrado 1987: 44, lám. I). La multiplicidad de cementerios alude a la pretensión de grupos sociales diferentes de individualizarse a partir de sus necrópolis exclusivas.

También en cada necrópolis destaca la existencia de tumbas semejantes, y difícilmente se identifica una única sepultura o una sola agregación destacada, lo que dificulta el reconocimiento de un único linaje que concentrara el poder. La presencia de varias tumbas semejantes señalaría la existencia de Casas, equiparables en importancia, rivalizando por el poder. Esto explicaría la competencia y el carácter heterárquico de las unidades sociales en los casos donde hay similares epicentros de poder contemporáneos como los túmulos destacados de El Cigarralejo o de Coimbra del Barranco Ancho o los monumentos funerarios sin asociar a tumbas concretas de Cabezo Lucero.

La naturaleza corporativa de las tumbas, además de referente individual, dotaría de sentido a la inclusión de objetos disociados del género del difunto y de la construcción social de la persona. Las armas, p. ej., señalarían el estatus de la persona enterrada. Pero, a diferencia de las sociedades tribales, en las que los elementos de género y estatus son los que articulan las relaciones sociales, en el caso ibérico las fórmulas de adscripción vigentes y los vínculos determinantes son de carácter político: la pertenencia a una Casa y el poder de esta. Y dentro de esta institución, las personas desempeñarían un papel acorde a su ordenamiento jerarquizado, pues no olvidemos que estas Casas están dirigidas por familias y personas poderosas.

Desde esa perspectiva, los objetos ritualizados a partir de su depósito en las tumbas se convierten en emblemas de poder y símbolos de autoridad política, además de marcadores personales de estatus, edad y género. Interpretaciones similares se han realizado en otras necrópolis del Mediterráneo Antiguo, como p. ej. en la Etruria tirrena (Riva 2009: 88-95). Este punto de vista, escasamente desarrollado en el ámbito ibérico, permite aproximarse a las estructuras de poder y las relaciones sociales.

Esta interpretación explicaría determinados objetos cuyas adscripciones no se entienden exclusivamente desde la asignación personal. Los innumerables ejemplos de ítems relacionados con el tejido en las tumbas de varones armados o las armas en tumbas infantiles y de mujeres no diluyen las asignaciones de género. Mas bien las complementan con su valor como emblemas ritualizados del poder económico y político de la Casa a la que pertenecían y que se exhibía en el funeral. Estos elementos incorporados a la tumba señalarían el control del ritual, la capacidad militar o las actividades generadoras de la riqueza de la Casa, más allá de los valores individuales de estatus, género o edad.

\section{CONSIDERACIONES FINALES}

El análisis expuesto ha subrayado el carácter de las necrópolis como lugares de memoria cuya agencia configura las dinámicas de poder de las sociedades ibéricas del sureste de la península ibérica, en especial en el siglo IV a. n. e. Desde esta perspectiva, se ha incidido en el rol de la comunidad en el marco teórico de las Sociedades de Casas, ya que, a pesar de las limitaciones impuestas por el registro funerario, se ha 
podido observar que el protagonismo del ritual recae en los participantes. Y es que la escenificación de los rituales ofrece estabilidad a la comunidad a través de su repetición e invariabilidad temporal constatando las relaciones de poder.

Los retazos de los rituales fosilizados en el contexto funerario informan sobre la relevancia de la generación fundadora, representada en la mayoría de los casos estudiados por tumbas dobles y femeninas. El análisis detallado de la ubicación espacial de estos enterramientos, su secuencia temporal, los discursos simbólicos de sus ajuares y la estructura de las tumbas muestran dinámicas que visibilizan el papel de la mujer ibera. Este va más allá de los roles de madre o esposa a los que se ha asociado en el modelo social basado en la aristocracia clientelar. Frente a las narrativas de subordinación femenina, se destaca la construcción de relatos complementarios donde los rasgos de individualidad de género, edad y estatus se enmarañan con la identidad colectiva de la Casa.

Las mujeres están presentes en las necrópolis ibéricas con voz propia, como personas notables para la comunidad con derecho a ser enterradas. Al analizar los ajuares de las tumbas identificadas como femeninas se observa una superposición de mensajes simbólicos, en parte debidos a la polisemia de los objetos, que invita a contrarrestar los binomios del tipo varón-armas. Los elementos relacionados con las actividades de hilado $\mathrm{y}$ tejido, hallados en tumbas masculinas y femeninas -pero también ausentes en estas últimas- no remiten solo a las habilidades o los valores que encarnan estos objetos asociados a la esfera femenina. Dicha narrativa se entremezcla con el discurso de la Casa para expresar la importancia de esta actividad productiva, mencionada en las fuentes grecolatinas y la iconografía ibérica, enfatizando el prestigio y poder que pudiera otorgar su control por parte de las elites representadas por hombres y mujeres.

Las mujeres están patentes en las necrópolis estudiadas a través de sus restos óseos y de sus huellas preservadas en los ajuares, vinculables con su participación directa en los rituales. Y también contamos con un par de esculturas funerarias, las damas de El Cigarralejo y de Guardamar que, a diferencia de la Dama de Baza, parece que estuvieron ubicadas en el exterior de las tumbas escenificando la relevancia de estas mujeres para la comunidad.

Por último, la estructura social y de poder que se dibuja a partir de estas evidencias funerarias se orienta hacia modelos heterárquicos, con grupos sociales equiparables detentando el poder. En otro estudio conectamos las viviendas con grupos "equiparables en rango y poder que despliegan similares estrategias materiales e inmateriales para su engrandecimiento y reproducción" (Grau Mira y Vives-Ferrándiz 2018: 98), algo que se adecua perfectamente al registro funerario ahora analizado. La existencia de necrópolis semejantes o de tumbas articuladoras de poderes variados en el seno de los cementerios habla de unas formas de poder no tan centralizadas como las de otros ámbitos.

Como hemos venimos considerando en este trabajo, en el amplio territorio de Iberia pudieron cohabitar diversos modelos sociales con bases comunes (desigualdad, parentesco metafórico y rasgos de jerarquización), pero cuyas estructuras más o menos inclusivas y de naturaleza más o menos corporativa responden a las diversas trayectorias regionales observables en el registro arqueológico. Con ello avanza el análisis de las variaciones territoriales en el seno de la amplia zona por donde se extiende la cultura ibérica ya que los estudios detallados de los rasgos locales hacen posible obtener una mayor resolución en la caracterización social de los grupos iberos y analizar las distintas dinámicas de la Edad del Hierro.

\section{AGRADECIMIENTOS}

M. ${ }^{a}$ A. García Luque nos permitió la consulta de su tesis doctoral inédita y V. Page del Pozo, directora del Museo de Arte Ibérico de El Cigarralejo, nos facilitó información y fotografías de las urnas de la tumba 452 de la necrópolis homónima, custodiadas en ese museo. Vaya también nuestro agradecimiento a I. Amorós López y los revisores anónimos por las correcciones y sugerencias para mejorar nuestro manuscrito.

\section{BIBLIOGRAFÍA}

Aranegui, C. 2008: "La prevalencia de representaciones femeninas: el caso de La Cultura Ibérica". En L. Prados Torreira y C. Ruiz López (eds.): Arqueología del Género. $1^{\text {er }}$ Encuentro Internacional en la UAM (Madrid 2005): 205-224. Universidad Autónoma de Madrid. Madrid.

Aranegui, C.; Jodin, A.; Llobregat, E.; Rouillard, P. y Uroz, J. 1993: La nécropole ibérique de Cabezo Lucero (Guardamar del Segura, Alicante). Collection Casa de Velázquez 41. Casa de Velázquez. Madrid - Alicante.

Beck, R. A. Jr. (ed.) 2007: The durable house: House Society models in Archaeology. Center for Archaeological Investigations Occasional Paper. Carbondale.

Bonet, H.; Grau, I. y Vives-Ferrándiz, J. 2015: “Estructura social y poder en las comunidades ibéricas de la franja central mediterránea". Arqueo Mediterrània 14: 251-272.

Carsten, J. y Hugh-Jones, S. (eds.) 1995: About the house. Lévi-Strauss and beyond. Cambridge University Press. Cambridge.

Castelo, R.; López Ruiz, C.; Prados Torreira, L.; Rodríguez-Shadow M. y Corona, C. 2017: "Un proyecto común. La exposición enfrentándose a la vida. Las mujeres ibéricas y las mujeres prehispánicas mesoamericanas. Un encuentro a través de la arqueología”. En L. Prados Torreira y C. Ruiz López (eds.): Museos arqueológicos y género. Educando en igualdad. Universidad Autónoma de Madrid. Madrid: $379-400$. 
Chapa, T. 2008: "Presencia infantil y ritual funerario en el mundo ibérico". En F. Gusi, S. Muriel y C. Olaria (eds.): Nasciturus, infans, puerulus vobis mater terra. Diputación de Castelló - Servei d'Investigacions Arqueològiques i Prehistòriques. Castelló: 619-641.

Chesson, M. S. 2003: "Households, houses, neighborhoods and corporate villages: modeling the Early Bronze Age as a House Society". Journal of Mediterranean Archaeology 16 (1): 79-102. https://doi.org/10.1558/jmea.v16i1.79

Cortell, E.; Juan, J.; Llobregat, E.; Reig, C.; Sala, F. y Segura, J. M 1992: "La necrópolis ibérica de La Serreta: resumen de la campaña de 1987". En Estudios de Arqueología Ibérica y Romana: Homenaje a E. Pla Ballester. Serie de Trabajos Varios 89. Servicio de Investigación Prehistórica - Diputación Provincial de Valencia. Valencia: 83-116.

Cuadrado, E. 1987: La necrópolis ibérica de “El Cigarralejo” (Mula, Murcia). Bibliotheca Praehistorica Hispana XXIII. Consejo Superior de Investigaciones Científicas. Madrid.

Cuadrado, E. 1995: "La dama sedente de El Cigarralejo (Mula, Murcia)". XXII Congreso Nacional de Arqueología (Vigo 1993) 2: 247-250. Xunta de Galicia. Vigo.

Díaz-Andreu, M. y Tortosa T. 1998: "Gender, symbolism and power in Iberian societies”. En P. P. A. Funari, M. Hall y S. Jones (eds.): Historical Archaeology. Back from the edge. Routledge. London: 99-121.

Driessen, J. 2010: "Spirit of place. Minoan Houses as major actors". En D. J. Pullen (ed.): Political economies of the Aegean Bronze Age. Oxbow. Oxford: 35-65.

García Cano, J. M. 1994: "El pilar estela de Coimbra del Barranco Ancho (Jumilla, Murcia)". Revista de Estudios Ibéricos 1: 173-202.

García Cano, J. M. 1997: Las necrópolis ibéricas de Coimbra del Barranco Ancho (Jumilla. Murcia) I, Las excavaciones y estudio analitico de los materiales. Universidad de Murcia. Murcia.

García Cano, J. M. 1999: Las necrópolis ibéricas de Coimbra del Barranco Ancho (Jumilla. Murcia). II. Análisis de los enterramientos, catálogo de materiales y apéndices antropológico, arqueozológico y paleobotánico. Universidad de Murcia. Murcia.

García Cano, J. M.; Gallardo Carrillo, J.; Ramos Martínez, F.; Martínez García, J.; Hernández Carrión, E.; Gualda Bernal, R. M. y Crespo Valero, J. M. 2016: Plan director del conjunto arqueológico Coimbra del Barranco Ancho, Jumilla. Patrimonio Inteligente. Murcia.

García Cano, J. M. y Gualda Bernal, R. M. 2019: Igualdad y desigualdad de género en la sociedad ibérica. El ejemplo de Coimbra del Barranco Ancho (Jumilla, Murcia). Centro de Estudios del Próximo Oriente y la Antigüedad Tardía. Murcia.

García Cano, J. M.; Page del Pozo, V.; Gallardo Carrillo, J.; Ramos Martínez, F.; Hernández Carrión, E. y Gil González, F. 2008: El mundo funerario ibérico en el altiplano Jumilla-Yecla (Murcia): la necrópolis de El Poblado de Coimbra del Barranco Ancho. Investigaciones de 1995-200. II Las incineraciones y los ajuares funerarios. Fundación Adendia. Murcia.

García Cardiel, J. 2017: "Las flautistas de Iberia. Mujer y transmisión de la memoria social en el mundo ibérico (siglos III-I a. C.)". Complutum 28 (1): 143-162. https://doi.org/10.5209/CMPL.58424

Gillespie, S. D. 2007: "When is a House?". En R. A. Beck, Jr. (ed.): The durable house: House Society models in Archaeology. Center for Archaeological Investigations Occasional Paper. Carbondale: 25-50.

Gómez Bellard, F. 2011: "Estudio antropológico de las cremaciones de La Serreta (Alcoy, Alicante)". Saguntum 43:103-123. https://doi.org/10.7203/sagvntvm.43.1237

González Reyero, S.; Rueda, C.; Herranz, A. B.; Alba Luzón, M.; Sánchez Gómez, M. L. y Rísquez, C. 2020: Memorias de Urkeatin. Nacer, vivir y morir en las sociedades iberas. Semana de la Ciencia y la Tecnología (Madrid 2020). http://hdl.handle.net/10261/222494

González-Ruibal, A. 2006: "House societies vs. kinship-based societies: an archaeological case from Iron Age Europe". Journal of Anthropological Archaeology 25 (1): 144-173. https://doi.org/10.1016/j.jaa.2005.09.002

González-Ruibal, A y Ruiz-Gálvez, M. L. 2016: "House Societies in the Ancient Mediterranean (2000-500 BC)". Journal of World Prehistory 29 (3): 217-336. https://doi.org/10.1007/s10963-016-9098-8

Grau Mira, I. 2002: La organización del territorio en el área central de la Contestania Ibérica. Publicacions Universitat d'Alacant. Alacant.
Grau Mira, I. 2007: "Dinámica social, paisaje y teoría de la práctica. Propuestas sobre la evolución de la sociedad ibérica en el área central del oriente peninsular". Trabajos de Prehistoria 64 (2): 119-142. https://doi.org/10.3989/tp.2007.v64.i2

Grau Mira, I. 2019: "Social dynamics in eastern Iberia Iron Age: between inclusive and exclusionary strategies". En B. X. Currás e I. Sastre (eds.): Alternative Iron Ages. Social theory from archaeological analysis. Routledge. Londres: 337-358.

Grau Mira, I. y Vives-Ferrándiz, J. 2018: "Entre casas y comunidades: formas de organización y relación social en el área oriental de la península ibérica (siglos V-II a. n. e.)". En A. Rodríguez, I. Pavón y D. M. Duque (eds.): Más allá de las casas. Familias, linajes y comunidades en la protohistoria peninsular. Universidad de Extremadura. Cáceres: 73-109.

Gualda Bernal, R. M. 2014: "La necrópolis del Poblado de Coimbra del Barranco Ancho (Jumilla, Murcia) desde una perspectiva del género. La singularidad de las tumbas femeninas con armas”. En P. D. Conesa Navarro, J. J. Martínez García, C. M. Sánchez Mondéjar, C. Molina Valero y L. García Carreras (eds.): Antigüedad in Progress... Actas del I Congreso Internacional de Jóvenes Investigadores del Mundo Antiguo (Murcia 2014): 193-207. Centro de Estudios del Próximo Oriente y la Antigüedad Tardía, Universidad de Murcia. Murcia.

Gualda Bernal, R. M. 2015a: "Señoras y aves en Coimbra del Barranco Ancho (Jumilla. Murcia)". Verdolay 14: 143-155.

Gualda Bernal, R. M. 2015b: "Representación y presencia del ave en la cultura ibérica. Su análisis en el ámbito funerario". En A. Fernández (ed.): I Encuentro de Jóvenes investigadores en Arqueología de la Región de Murcia: de la Prehistoria a la Arqueología Industrial: $227-$ 269. Universidad de Murcia. Murcia.

Gualda Bernal, R. M. 2018: “Oro, plata... y género en las necrópolis del poblado de Coimbra del Barranco Ancho (Jumilla) y de El Cigarralejo (Mula)". En R. M. Gualda y E. Hernández Carrión (eds.): El legado de Jerónimo Molina a la Arqueología (Jumilla 2013). Centro de Estudios del Próximo Oriente y la Antigüedad Tardía, Universidad de Murcia. Murcia: 89-103.

Herranz, A. B.; Rueda, C. y Rísquez, C. 2016: "Patrimonio cultural y género: Propuestas para el programa turístico Viaje al Tiempo de los Iberos". PH: Boletín del Instituto Andaluz del Patrimonio Histórico 89: $150-152$.

Izquierdo Peraile, I. 1998: "La imagen femenina del poder. Reflexiones en torno a la feminización del ritual funerario en la cultura ibérica". Actas del Congreso Internacional Los Iberos, Príncipes de Occidente (Barcelona 1998). Saguntum. PLAV, Extra 1. Universitat de València. València: 185-193.

Izquierdo Peraile, I. 1998-1999: “Las 'damitas' de Moixent en el contexto de la plástica y la sociedad ibérica”. Lucentum 17-18: 131-147. https://doi.org/10.14198/lvcentvm1998-1999.17-18.06

Izquierdo Peraile, I. 2000: Monumentos funerarios ibéricos: Los pilaresestela. Serie de Trabajos Varios 98. Servicio de Investigación Prehistórica - Diputación Provincial de Valencia. Valencia.

Izquierdo Peraile, I. 2007: "Arqueología de la muerte y el estudio de la sociedad: Una visión desde el género en la cultura ibérica”. Complutum 18: 247-161.

Izquierdo Peraile, I. 2008: “Arqueología, iconografía y género: códigos en femenino del imaginario ibérico". Verdolay 11: 121-142.

Izquierdo Peraile, I. 2012: "Mujeres y plantas en el imaginario ibérico de la muerte". En L. Prados Torreira, C. López Ruiz y J. Parra Camacho (eds.): La Arqueología funeraria desde una perspectiva de género. II Jornadas Internacionales de Arqueología y Género en la UAM (Madrid 2010): 277-298. Universidad Autónoma de Madrid. Madrid.

Izquierdo Peraile, I. y Prados Torreira, L. 2004: "Espacios funerarios y religiosos en la cultura ibérica: lecturas desde el género en Arqueología”. Spal 13: 155-180. https://doi.org/10.12795/spal.2004.i13.06

Joyce R. A. y Gillespie, S. D. 2000: Beyond kinship. Social and material reproduction in House Societies. University of Pennsylvania Press. Philadelphia.

Lévi-Strauss, C. 1981: La vía de las máscaras. Siglo XXI Editores. México.

López Ruiz, C. 2008: "Una aproximación a la imagen de la mujer en el mundo ibérico". En S. González Reyero, M. Pérez Ruiz y C. Isabel Bango García: Una nueva mirada sobre el patrimonio histórico. Li-

Trab. Prehist., 78, N. . 2, julio-diciembre 2021, pp. 309-324, ISSN: 0082-5638

https://doi.org/10.3989/tp.2021.12278 
neas de investigación arqueológica en la UAM. Universidad Autónoma de Madrid. Madrid: 217-236.

Lucas, R. 2001-2002: "Entre dioses y hombres: el paradigma de 'El Cigarralejo’ (Mula, Murcia)”. Anales de Prehistoria y Arqueología 16-17: 147-158.

Lucas, R. y Ruano, E. 1998: "El complejo arqueológico de 'El Cigarralejo"'. Boletín de la Asociación Española de Amigos de la Arqueología 38: 103-121.

Malgosa, A.; Subirà, M. E.; Carrasco, T. y Castellana, C. 1999: "Informe antropológico de las necrópolis del Poblado". En J. M. García Cano: Las necrópolis ibéricas de Coimbra del Barranco Ancho (Jumilla. Murcia). II. Análisis de los enterramientos, catálogo de los materiales y apéndices antropológico, arqueozoológico y paleobotánico. Universidad de Murcia. Murcia: 131-154.

Mata, C.; Soria, L. y Blasco, M. 2020: "Artesanías evanescentes de la Edad del Hierro en la península ibérica”. Actualidad de la investigación arqueológica en España II (2019-2020). Conferencias impartidas en el Museo Arqueológico Nacional. Museo Arqueológico Nacional. Madrid: 29-45. http://www.man.es/man/dam/ jcr:5edb1dd3-be8c-427b-a625-3ba9215499dd/2020-aae-ciclo-ii.pdf (consulta 09-07-2021).

Muñoz Amilibia, A. M. 1987: "La escultura funeraria de la necrópolis de Coimbra del Barranco Ancho (Jumilla, Murcia)". Archivo de Prehistoria Levantina 17: 229-255.

Prada, M. de y Cuadrado, E. 2019: La necrópolis ibérica de El Cigarralejo (Mula, Murcia). Segunda parte. Monografías del Museo de Arte Ibérico de El Cigarralejo. Murcia.

Prados Torreira, L. 2007: "Mujer y espacio sagrado: haciendo visibles a las mujeres en los lugares de culto de época ibérica”. Complutum 18: $217-125$

Prados Torreira, L. 2010: "La mujer aristocrática en el paisaje funerario ibérico". En T. Chapa e I. Izquierdo Peraile (eds.): La Dama de Baza. Un viaje femenino al más allá. Ministerio de Cultura. Madrid: 223242 .

Prados Torreira, L. 2011-2012: "El ritual funerario durante la II Edad del Hierro en la Península Ibérica. Algunas reflexiones sobre los grupos marginados por la investigación". Cuadernos de Prehistoria y Arqueología 37-38: 317-331. https://doi.org/10.15366/cupauam2012.38.016

Prados Torreira, L. 2012: "Si las muertas hablaran... Una aproximación a los contextos funerarios de la cultura ibérica”. En L. Prados Torreira, C. López Ruiz y J. Parra Camacho (eds.): La Arqueología funeraria desde una perspectiva de género. II Jornadas Internacionales de Arqueología y Género en la UAM (Madrid 2010): 233-255. Universidad Autónoma de Madrid. Madrid.

Prados Torreira, L.; Izquierdo Peraile, I.; Sánchez, C.; Santos, J. A.; López Ruiz, C.; García Castañeda, A. y Parra Camacho, J. 2011: Arqueología y género: mujer y espacio sagrado. Haciendo visible a las mujeres en los lugares de culto de la época ibérica. Instituto de la Mujer. Madrid._https://cpage.mpr.gob.es/producto/arqueologia-ygenero/ (consulta 23-02-2021).

Prados Torreira, L.; López Ruiz, C. y Parra Camacho, J. (eds.) 2012: La Arqueología funeraria desde una perspectiva de género. II Jornadas Internacionales de Arqueología y Género en la UAM (Madrid 2010). Universidad Autónoma de Madrid. Madrid.

Quesada, F. 1989: "Informática en Arqueología: un ejemplo aplicado al estudio de jerarquización en necrópolis ibéricas". Boletín de la Asociación Española de Amigos de la Arqueología 27: 36-44.

Quesada, F. 2010: "Las armas de la sepultura 155 de la necrópolis de Baza”. En T. Chapa e I. Izquierdo Peraile (eds.): La Dama de Baza. Un viaje femenino al más allá. Ministerio de Cultura. Madrid: 149169.

Quesada, F. 2012: "Mujeres, amazonas, tumbas y armas: una aproximación transcultural". En L. Prados Torreira, C. López Ruiz y J. Parra Camacho (eds.): La Arqueología funeraria desde una perspectiva de género. II Jornadas Internacionales de Arqueología y Género en la UAM (Madrid 2010): 317-364. Madrid.

Rafel, N. 2007: "El textil como indicador de género en el registro funerario ibérico". Treballs d'Arqueologia 13: 115-146.
Reig, C. 2000: "El armamento de la necrópolis ibérica de La Serreta de Alcoi (Alicante, España)". Gladius 20: 75-117. https://doi.org/10.3989/gladius.2000.65

Ripollés Adelantado, E.; Fortea Cervera, L.; Ferrer García, C. y VivesFerrándiz Sánchez, J. 2016: "Contar contigo. Perspectivas de género en el proyecto de difusión patrimonial de la Bastida de Les Alcusses (Moixent, Valencia)". PH: Boletín del Instituto Andaluz del Patrimonio Histórico 89: 159-162.

Rísquez, C. y García Luque, M. A. 2007a: “¿Actividades de mantenimiento en el registro funerario? El caso de las necrópolis íberas". Treballs d'Arqueologia 13: 147-173.

Rísquez, C. y García Luque, M. A. 2007b: "Mujeres en el origen de la aristocracia ibera. Una lectura desde la muerte". Complutum 18: 263 270.

Rísquez, C. y García Luque, M. A. 2012: “Identidades de género y prácticas sociales en el registro funerario ibérico. La necrópolis de El Cigarralejo”. En L. Prados Torreira, C. López Ruiz y J. Parra Camacho (eds.): La Arqueología funeraria desde una perspectiva de género. II Jornadas Internacionales de Arqueología y Género en la UAM (Madrid 2010): 257-276. Universidad Autónoma de Madrid. Madrid.

Rísquez, C.; García Luque, M. A. y Hornos, F. 2010: "Mujeres y mundo funerario en las necrópolis ibéricas". En T. Chapa e I. Izquierdo Peraile (eds.): La Dama de Baza. Un viaje femenino al más allá. Ministerio de Cultura. Madrid: 259-278.

Rísquez, C. y Hornos, F. 2005: "Mujeres iberas. Un estado de la cuestión”. En M. Sánchez Romero (ed.): Arqueología y género. Universidad de Granada. Granada: 283-333.

Riva, C. 2009: The urbanisation of Etruria. Cambridge University Press. Cambridge.

Rosa, H. 2019: “La 'resonancia' como concepto fundamental de una sociología de la relación con el mundo". Diferencias. Revista de Teoría Social Contemporánea 1 (7): 71-81.

Ruano Ruiz, E. 1994: "El amor y el matrimonio entre los iberos". Espacio, Tiempo y Forma. Serie II, Historia Antigua 7: 141-163. https://doi.org/10.5944/etfii.7.1994.4237

Rueda, C.; Rísquez, C.; Herranz, A. B.; Hornos, F. y García Luque, M. A 2016: Las edades de las mujeres iberas. La ritualidad femenina en las colecciones del Museo de Jaén. Catálogo de la exposición. Universidad de Jaén - Diputación de Jaén - Delegación Territorial de Cultura, Turismo y Deporte en Jaén. Junta de Andalucía, Museo de Jaén. Jaén.

Ruiz-Gálvez, M. 2018: “Sociedad de clase o... 'Sociedad de Casa’? Reflexiones sobre la estructura social de los pueblos de la Edad del Hierro en la península ibérica”. En A. Rodríguez, I. Pavón y D. M. Duque (eds.) Más allá de las casas. Familias, linajes y comunidades en la protohistoria peninsular. Universidad de Extremadura. Cáceres: $13-40$.

Ruiz, A. 2008: “Iberos". En F. Gracia Alonso (ed.): De Iberia a Hispania. Ariel. Barcelona: 733-844.

Ruiz, A. y Molinos, M. 2018: “Genealogía, matrimonio y residencia en el proceso político de los iberos del Alto Guadalquivir”. En A. Rodríguez, I. Pavón y D. M. Duque (eds.): Más allá de las casas. Familias, linajes y comunidades en la protohistoria peninsular. Universidad de Extremadura. Cáceres: 41-72.

Ruiz, A.; Rísquez, C.; Hornos, F. 1992: "Las necrópolis ibéricas en la Alta Andalucía”. En J. Blánquez y V. Antona (eds.): Congreso de Arqueología ibérica: las necrópolis (Madrid 1991): 397-430. Universidad Autónoma de Madrid. Madrid.

Ruiz, A.; Rísquez, C. y Molinos, M. 2011: "Túmulos, linajes y clientes: la construcción del paisaje funerario aristocrático en el sur de la Península Ibérica". En A. Naso (ed.): Tumuli e sepolture monumentali nella Protostoria Europea. Atti del Convegno Internazionale (Celano 2000). Verlag des Römisch-Germanischen Zentralmuseums. Mainz: 261-275.

Sanmartí, J. 2009: "Colonial relations and social change in Iberia (Seventh to Third centuries BC)". En M. Dietler y C. López-Ruiz (eds.) Colonial encounters in Ancient Iberia. The University of Chicago Press. Chicago - London: 49-91.

Sala, F. y Hernández, L. 1998: "La necrópolis de El Puntal (Salinas, Alicante): aspectos funerarios ibéricos del siglo IV aC en el corredor del Vinalopó". Quaderns de prehistòria i arqueologia de Castelló 19. 221-266.

Trab. Prehist., 78, N. ${ }^{\circ} 2$, julio-diciembre 2021, pp. 309-324, ISSN: 0082-5638 https://doi.org/10.3989/tp.2021.12278 
Santonja, M. 1985-1986: "Necrópolis ibérica de El Cigarralejo (Mula, Murcia). Estudio anatómico y métrico (I)". Boletín de la Asociación Española de Amigos de la Arqueología 21: 28-36.

Santonja, M. 1993: "Necrópolis ibérica de 'El Cigarralejo'. Estudio osteológico comparado con los ajuares". Espacio, Tiempo y Forma. Serie II, Historia Antigua 6: 297-346.

https://doi.org/10.5944/etfii.6.1993.4217

Santos, J. A. 1989: “Análisis social de la necrópolis ibérica de El Cigarralejo y otros contextos funerarios de su entorno". Archivo Español de Arqueología 62 (159): 71-100.

Subirà, M. E. 2019: “Anexo VI.- Los restos humanos”. En J. M. García Cano y R. M. Gualda Bernal: Igualdad y desigualdad de género en la sociedad ibérica. El ejemplo de Coimbra del Barranco Ancho (Jumilla, Murcia). Centro de Estudios del Próximo Oriente y la Antigüedad Tardía. Murcia: 82-83.

Subirà, M. E.; Ruiz, J.; García Cano, J. M. y Gallardo. J. 2008: "La necrópolis del Poblado (Jumilla. Murcia). Datos antropológicos". En A. M. Adroher y J. Blánquez (eds.): $1^{\text {er }}$ Congreso Internacional de Arqueología Bastetana (Baza 2008) 2: 59-69. Universidad Autónoma de Madrid - Universidad de Granada. Madrid - Granada.
Schubart, H. 2002-2003: "Platos fenicios de occidente". Lucentum 21-22: 45-61. https://doi.org/10.14198/lvcentvm2002-2003.21-22.03

Thomas, J. 2015: "House societies and founding ancestors in Early Neolithic Britain". En C. Renfrew, M. Boyd e I. Morley (eds.): Death rituals, social order and the archaeology of immortality in the Ancient World. Cambridge University Press. Cambridge: 138-152.

Uroz, H. y Uroz, J. 2010: "Rito, religión y sociedad de la Guardamar ibérica. La necrópolis de Cabezo Lucero”. En A. García Menargues (ed.): Guardamar del Segura. Arqueología y Museo. Publicaciones del MARQ. Alacant: 90-113.

Vives-Ferrándiz, J. 2013: "Del espacio doméstico a la estructura social en un oppidum ibérico. Reflexiones a partir de La Bastida de les Alcusses". En S. Gutiérrez Lloret e I. Grau Mira (eds.): De la estructura doméstica al espacio social. Lecturas arqueológicas del uso social del espacio. Universitat d'Alacant. Alacant: 95-111.

Waterson, R. 1995: "Houses and hierarchies in island Southeast Asia". En J. Carsten y S. Hugh-Jones (eds.): About the house: Lévi-Strauss and beyond. Cambridge University Press. Cambridge: 47-68.

Trab. Prehist., 78, N. ${ }^{\circ}$ 2, julio-diciembre 2021, pp. 309-324, ISSN: 0082-5638

https://doi.org/10.3989/tp.2021.12278 